\title{
Influence of Skin Subjective Symptoms on Sleep Quality in Patients with Cutaneous Disorders: A Study of 287| Subjects
}

This article was published in the following Dove Press journal: Clinical, Cosmetic and Investigational Dermatology

\author{
Bruno Halioua' \\ Laurent Misery iD $^{2,3}$ \\ Sophie Seite iD ${ }^{4}$ \\ Veronique Delvigne ${ }^{4}$ \\ Clara Chelli (D) ${ }^{5}$ \\ Jonathan Taieb ${ }^{6}$ \\ Charles Taieb (D) ${ }^{7,8}$ \\ 'Dermatologue, Paris, France; ${ }^{2}$ Univ \\ Brest, LIEN, F-29200, Brest, France; \\ ${ }^{3}$ Department of Dermatologie, \\ University Hospital of Brest, Brest, \\ France; ${ }^{4}$ La Roche-Posay Laboratoire \\ Dermatologique, Levallois-Perret, France; \\ ${ }^{5}$ Department of Dermatology- \\ Venereology, Robert-Debré Hospital, \\ Reims, France; ${ }^{6} \mathrm{APHP}$, Hôtel Dieu, \\ Centre du Sommeil et de la Vigilance, \\ Paris, France; ${ }^{7}$ European Market \\ Maintenance, Assessment, Patients \\ Priority Department, Fontenay-sous- \\ Bois, France; ${ }^{8}$ Hôpital Necker Enfants \\ Malades, Paris, France
}

Introduction: Previous studies showed more sleep disturbance (SD) in patients with cutaneous disorders (CD). During CD, unpleasant subjective symptoms [USS], such as itch, pain and others (tingling, burning, or tightness) have a negative influence on sleep quality. This study aims to evaluate the prevalence of SD in CD patients and to identify the influence of itch, pain and other unpleasant sensations on SD.

Materials and Methods: An international, anonymized real-life survey was conducted with individuals [18-75 years], with physician-confirmed CD, or without CD. The 25 items covered sociodemographic characteristics, feeling of overall sleep quality and skin unpleasant sensations. Severity of SD and unpleasant sensations were assessed using a $10-\mathrm{cm}$ Visual Analogue Scale (VAS).

Results: From 3834 analyzed questionnaires, 2871 (67.3\%) were in the CD group and 863 $(32.7 \%)$ in the control group. Patients with CD had significantly more SD (71.2\% vs $32.7 \%$ in the control group, $\mathrm{p}<0.0001)$. CD patients without any reported unpleasant sensation were at higher risk for SD than control subjects (OR 1,362 [95\% CI 1.975-2.405] p=0.0013). SS were highly associated with SD (OR 1.641 [95\% CI 1.393-1.933] $\mathrm{p}<0.0001$ ). Pruritus, pain and intermediate sensations were significant predictors of $\mathrm{SD}$, with odds ratios of 1.670 , 1.625 and 1.326, respectively. VAS sleep scores were strongly associated with pruritus (r: $0.25, \mathrm{p}<0.0001)$ and pain $(\mathrm{r}: 0.25 \mathrm{p}<0.0001)$ severity ratings.

Discussion: SD is a common problem for patients with $\mathrm{CD}$. Patients with subjective symptoms suffer more from SD, suggesting that they are aggravating factors, but are likely not the only reason for SD in CD patients. We found that during $\mathrm{CD}$, intermediate sensations also contribute to SD. Despite some limitations and the potential bias due to the study design, our results confirm for the first time on an international level the influence of subjective symptoms on sleep quality in patients with CD.

Keywords: unpleasant sensations, sleep quality, cutaneous disorders

\section{Introduction}

Sleep, which occupies approximately one-third of the lives of human beings, is essential for mental and physical health and well-being. ${ }^{1}$ Sleep disturbances (SDs) are distressing and disabling conditions that are frequently reported in chronic medical illnesses with significant quality-of-life impairment. ${ }^{2,3}$ Previous studies have shown more SD in patients with cutaneous disorders (CD) ${ }^{4}$ such as psoriasis, $^{5-8}$ atopic dermatitis, ${ }^{9-11}$ vitiligo, ${ }^{12,13}$ acne, ${ }^{14}$ urticaria, $^{15,16}$ prurigo nodularis, ${ }^{17}$ hidradenitis suppurativa ${ }^{18}$ and lichen planus. ${ }^{19} \mathrm{SD}$ can aggravate the
Correspondence: Bruno Halioua Dermatologue, 56 Boulevard SaintMarcel, Paris, 75005, France

Email haliouab@yahoo.fr 
underlying $\mathrm{CD}$ and cause decreased health-related quality of life (HRQoL). ${ }^{5,20,21}$ SDs are often under-recognized and under-reported in patients with $\mathrm{CD}$ because of the absence of systematic or specific questioning by dermatologists. The pathogenesis of SD in patients with $\mathrm{CD}$ is complex and multifactorial. Unpleasant subjective symptoms such as itch and pain are known to have a negative influence on the sleep quality of $\mathrm{CD}$ patients, causing both difficulty in falling asleep and frequent awakenings from sleep. ${ }^{4,5,18,22-29}$ In addition to pruritus and pain, patients with CD can suffer from other unpleasant symptoms, such as tingling, burning or tightness. ${ }^{30}$ The current state of knowledge about the influence of these other unpleasant sensations on SD in patients with $\mathrm{CD}$ is limited and not fully understood. The aim of the present study was to evaluate the prevalence of sleep disturbance in CD patients and to identify the influence of itch, pain and other unpleasant sensations on SD.

\section{Materials and Methods}

An international, anonymized survey was conducted from December 2018 to January 2019 via a digital questionnaire in France, Brazil, China, Russia and the USA on participants with self-reported dermatosis (respondents reported that the diagnosis had been confirmed by a physician) or without dermatosis (control-group), using a representative sample of the general adult population aged between 18 and 75 years of age. The survey was conducted by means of local Internet databases of users who agreed to participate in surveys. It complied with local data protection laws and used completely anonymized data. No participant refused to participate. The evaluation was conducted in accordance with the relevant ethical guidelines.

In fact, as this study did not involve any patient contact and was completely anonymous, approval from the ethical review board was not necessary. Each subject was informed of the nature of the questionnaire and confirmed his or her agreement before being able to respond. The GPRD was respected.

The CD group was defined as the individuals with at least one self-reported dermatosis. Subjects had to confirm that their dermatosis was clinically confirmed by a physician. Exclusion criteria included a non-physician confirmed dermatosis and age greater than 75 years.

The questionnaire was composed of items covering the following: 1) Sociodemographic characteristics. 2) Individual's subjective feeling of overall sleep quality, that was measured using a $10-\mathrm{cm}$ Sleep Disturbance Visual
Analogue Scale (SD-VAS). Scores of the SD-VAS ranged from 0 (no SD) to 10 points (worst SD). SD VAS scoring was categorized as mild ( $>0$ to $<3$ points), moderate ( $\geq 3$ to $<7$ points) and severe or very severe $\mathrm{SD}$ ( $\geq 7$ to 10 points). The SD-VAS is a sensitive, reproducible, reliable and validated measure $^{31}$ for the evaluation of sleep quality. Results of SD-VAS data are presented as $95 \%$ confidence intervals for the means. 3) Presence of skin unpleasant sensations, such as pain, itch, tingling, burning, or tightness. Three standardized 10-point visual analogue scales (VAS) were used to measure the intensity of itch, pain, and intermediate sensations (tingling, numbness, burning, and tightness); an intensity of 0 meant no symptoms, and 10 indicated the worst possible imaginable sensations.

Based on clinical evaluation, male and female patients were divided into four clinical groups, considering the presence or absence of symptoms and the type of symptoms.

1. Absence of skin unpleasant sensation (pruritus, pain, burning, tightness, tingling, numbness) (Intermediate sensations VAS Scoring, Itch VAS scoring and Pain VAS scoring $=0$ ).

2. Presence of intermediate sensations without pruritus or pain (Itch VAS scoring and Pain VAS scoring =0).

3. Greater feeling of pruritus associated or not with pain and intermediate sensations (the intensity of pruritus evaluated by VAS is greater than that of pain).

4. Greater feeling of pain associated or not with pruritus and intermediate sensations (the intensity of pain evaluated by VAS is greater than that of pruritus). Control population included subjects who had no subjective symptoms (no burning, tightness, tingling, numbness, pruritus and pain).

\section{Data Analyses}

Statistical analysis was performed using Stata 7.0 (Stata corporation, College Station, TX, USA). Data concerning adult individuals between 18 and 75 years of age with at least one dermatosis were extracted from the survey database. Quantitative variables are expressed as the means and standard deviations.

Qualitative variables are expressed as frequencies and percentages. Bivariate analyses involving categorical or qualitative variables were carried out with chi-square statistics. Quantitative variables were compared using the Student's test. The presence of a relationship between quantitative features was tested using Pearson's correlation coefficient for parameters consistent with a normal distribution and 


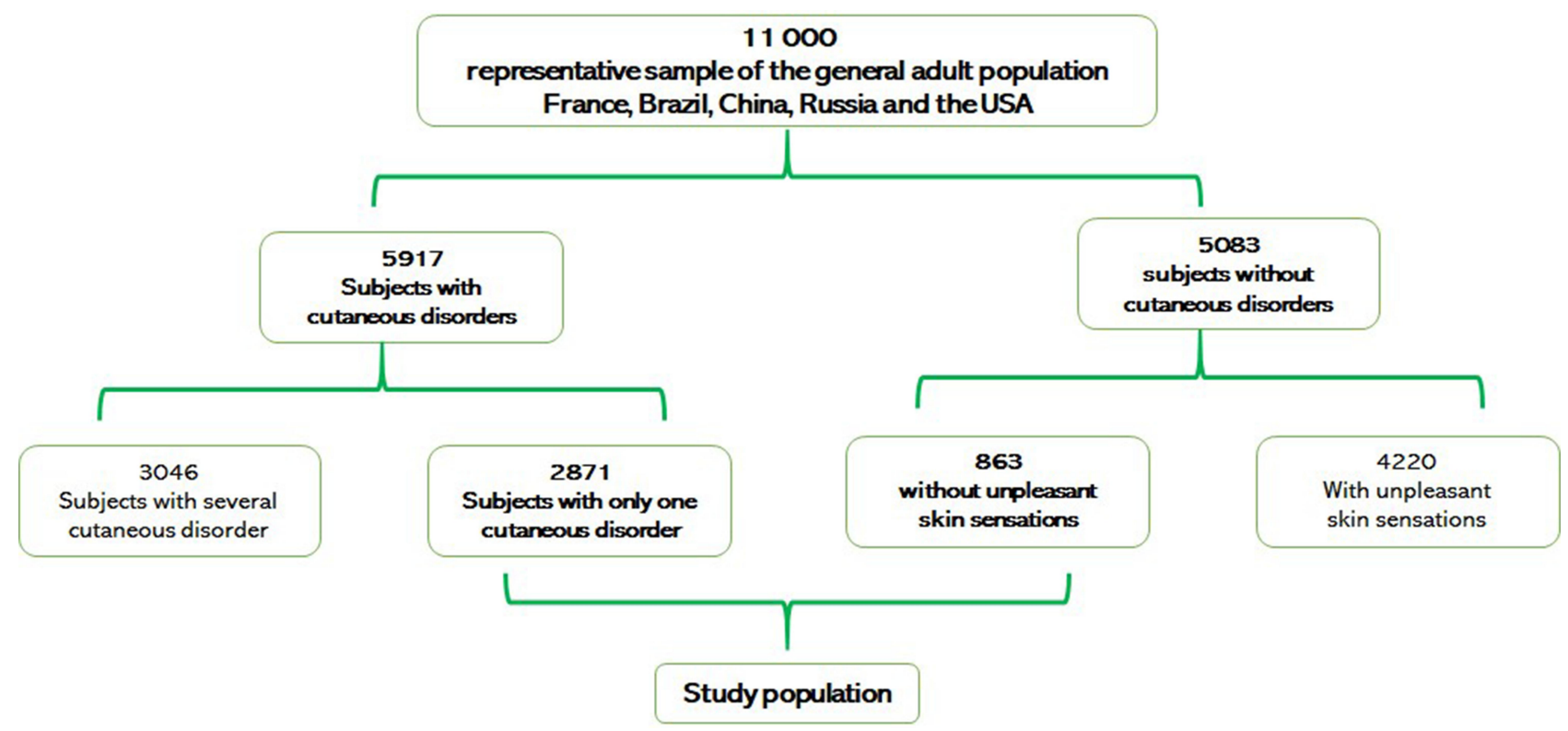

Figure I Study population.

Spearman correlation coefficient in cases of non-compliance with a normal distribution. A p-value of 0.05 was considered to indicate a statistically significant difference.

\section{Results}

\section{Demographic Characteristics of Patients with Cutaneous Disorders}

A total of 11,000 individuals participated in the survey, and data from 3834 of them were usable for statistical analysis: $2871(67.3 \%)$ from the CD group and 863 $(32.7 \%)$ from the control-group (Figure 1). The recruited patient group with CD [Acne $(n=1044)$; Psoriasis $(n=163)$; Atopic dermatitis $(n=254)$; Contact dermatitis $(n=147)$; Rosacea $(n=201)$; Vitiligo $(n=50)$; Seborrheic dermatitis $(n=195)$; Scalp disorders $(n=216)$; Photo dermatosis $(n=422)$; Other skin disorders $(n=179)]$ consisted of 1306 males and 1565 females (age $39.4 \pm 14.5$ years, range 18-74 years). Details regarding the patient demographics of the study sample are summarized in Table 1.

The 2871 subjects suffering from skin disorders were individualized into 4 groups, considering the presence or absence of symptoms and the type of symptom.

- A total of $182(6.3 \%)$ patients felt no pruritus, no pain and no intermediate sensation (burnings, tightness, tingling, numbness) (Intermediate sensations VAS Scoring, Itch VAS scoring and Pain VAS scoring $=0$ ).

- A total of 205 (7.1\%) subjects felt intermediate sensations without pruritus and pain (Intermediate sensations
VAS Scoring: from 0.1 to 10 , Itch VAS scoring and Pain VAS scoring $=0$ ).

- A total of 2325 (81\%) subjects felt more significant pruritus associated or not with pain and/or intermediate sensations (Itch VAS scoring from 0.1 to 10 and higher than Pain VAS scoring).

- A total of 159 (5.5\%) subjects felt more important pain associated or not with pruritus and intermediate sensations (Pain VAS scoring from 0.1 to 10 and higher than Itch VAS scoring).

Information on the prevalence rates of pruritus, pain and intermediate sensations for each skin disease is provided in Table 2.

\section{Prevalence and Intensity of Sleep Disorders}

Sociodemographic and clinical characteristics of patients from the CD group and the control group are summarized in Table 3. Patients suffering from CD were significantly younger than the control ones $(39.41 \pm 14$, versus $43.73 \pm$ 14.89, p: 2.42 E-06). We found a significantly higher prevalence of $\mathrm{SD}$ among patients with $\mathrm{CD}(71,2 \%$ vs $32.7 \%$ in the patient control-group, p: 646E-88). Patients with $\mathrm{CD}$ were at a significantly increased risk for SD when compared with control subjects (OR 2.179 [95\% CI 1.128-1.644] $\mathrm{p}<0.0001)$. Patients with asymptomatic CD were at a significantly increased risk for SD when compared with control subjects (OR $1.362 \quad[95 \%$ CI 
Table I Demographic Data of Cutaneous Disorders (CD) Patients and Control Subjects

\begin{tabular}{|c|c|c|c|c|}
\hline & & $\begin{array}{l}\text { Patient Group with CD, } \\
\mathbf{N}(\%)\end{array}$ & $\begin{array}{l}\text { Control Subjects, } \\
\text { N (\%) }\end{array}$ & $\mathbf{p}$ \\
\hline & Total & $287 \mid$ & 863 & \\
\hline Gender & $\begin{array}{l}\text { Male } \\
\text { Female }\end{array}$ & $\begin{array}{l}1306(45.5) \\
\text { I565 (54.5) }\end{array}$ & $\begin{array}{l}529(61.3) \\
334(38.7)\end{array}$ & 0.814292 \\
\hline Age & $\begin{array}{l}\text { Mean } \\
18-29 \text { years } \\
30-39 \text { years } \\
40-49 \text { years } \\
50-59 \text { years } \\
60-64 \text { years } \\
>60 \text { years }\end{array}$ & $\begin{array}{l}39.44 \\
903(31.5) \\
656(22.8) \\
588(20.5) \\
378(13.2) \\
164(5.7) \\
346(6.3)\end{array}$ & $\begin{array}{l}44,68 \\
167(19.4) \\
179(20.7) \\
188(21.8) \\
149(17.3) \\
64(7.4) \\
180(13.4)\end{array}$ & $8.745 \mathrm{E}-18$ \\
\hline Phototype & $\begin{array}{l}\text { Phototype I } \\
\text { Phototype II } \\
\text { Phototype III } \\
\text { Phototype IV } \\
\text { Phototype V } \\
\text { Phototype VI }\end{array}$ & $\begin{array}{l}353(12.3) \\
786(27.4) \\
1041(36.3) \\
448(15.6) \\
110(3.8) \\
133(4.6)\end{array}$ & $\begin{array}{l}100(11.6) \\
220(25.5) \\
334(38.7) \\
149(17.3) \\
30(3.5) \\
30(3.5)\end{array}$ & \\
\hline
\end{tabular}

1.975-2.405] p: 0.0013). However, there was no difference in the severity of SD between patients suffering from asymptomatic $\mathrm{CD}$ and control subjects $(3.56 \pm 2.35$ vs $3.54 \pm 2.32$, p: 0.92).

The prevalence of SD was not significantly different between males and females $(69.4 \%$ in males and $72.7 \%$ in females, p: 0.49). The prevalence of SD was significantly higher after 40 years in females $(537 / 113847.2 \%$ in women versus 324/907 35.7\% in men p: 1.81E-7) (Table 4).

The severity of SD was significantly higher in subjects suffering from CD than in controls $(4.13 \pm 2.51$ if dermatosis versus $3.54 \pm 2.32$ for control people, $p=0.0019)$. The severity of SD was significantly higher in females $(4.36 \pm$ 2.56 versus $3.84 \pm 2.411 .85$ E-6).
Symptom Predictors of Sleep Disturbance The Presence of Subjective Symptoms Was Highly Associated with SD (Adjusted HR) $1.64 \mathrm{I}([95 \% \mathrm{Cl}$ I.393-I.933], $\mathrm{p}<0.0001)$

Pruritus, skin pain and intermediate sensations are significant predictors of sleep disturbance, with odds ratios of 1.670 [95\% CI 1.417-1.967], p<0.0001), 1.625 [95\% CI $1.345-1.962$ ], $\mathrm{p}<0.0001)$ and 1.326 [95\% CI 1.087-1.617], $\mathrm{p}<0.0001$ ), respectively.

The prevalence of SD was not significantly different in people suffering from itching compared to those suffering from pain $(74.3 \%$ versus $72.3 \%$, p: 0.93$)$. The presence of $\mathrm{SD}$ in people suffering from pruritus was significantly greater than in those with intermediate sensations $(74.3 \%$

Table 2 Prevalence of Pruritus, Pain and Intermediate Sensations Among Cutaneous Disorders Group

\begin{tabular}{|l|l|l|l|l|}
\hline & Pruritus & Pain & $\begin{array}{l}\text { Intermediate } \\
\text { Sensations }\end{array}$ & Asymptomatic \\
\hline Acne $n=1044(36.36 \%)$ & $829(79.4 \%)$ & $59(5.7 \%)$ & $79(7.6 \%)$ & $97(7.4 \%)$ \\
Psoriasis $n=163(5.67 \%)$ & $126(77.3 \%)$ & $13(8.0 \%)$ & $9(5.5 \%)$ & $15(9.2 \%)$ \\
Atopic dermatitis $n=254(8 ; 84 \%)$ & $229(90.2 \%)$ & $9(3.5 \%)$ & $9(3.5 \%)$ & $7(2.8 \%)$ \\
Contact dermatitis $n=147(5.12 \%)$ & $130(88.4 \%)$ & $7(4.8 \%)$ & $3(2.0 \%)$ & $7(4.8 \%)$ \\
Rosacea $n=201(7 \%)$ & $144(71.6 \%)$ & $13(6.5 \%)$ & $22(10.9 \%)$ & $22(10.9 \%)$ \\
Vitiligo $n=50(1.74 \%)$ & $40(80.0 \%)$ & $1(2.0 \%)$ & $5(10.0 \%)$ & $4(8.0 \%)$ \\
Seborrheic dermatitis $n=195(6.79 \%)$ & $162(83.1 \%)$ & $8(8.0 \%)$ & $18(9.2 \%)$ & $7(3.6 \%)$ \\
Scalp disorders $n=216(7.52 \%)$ & $181(83.8 \%)$ & $9(4.2 \%)$ & $20(9.3 \%)$ & $6(2.8 \%)$ \\
Photodermatosis $n=422(14.70 \%)$ & $344(81.5 \%)$ & $28(6.6 \%)$ & $26(6.2 \%)$ & $24(5.7 \%)$ \\
Other skin disorders $n=179(6.23 \%)$ & $140(78.2 \%)$ & $12(6.7 \%)$ & $14(7.8 \%)$ & $13(7.3 \%)$ \\
\hline
\end{tabular}


Table 3 Sociodemographic and Clinical Characteristics of Patients with and without Sleep Disorders (SD)

\begin{tabular}{|c|c|c|c|c|}
\hline & & $\begin{array}{l}\text { Patients with SD } \\
n=287 \text { I }\end{array}$ & Patient Control Group without SD n=863 & $P$ value \\
\hline \multirow[t]{4}{*}{ Skin $=$ disorders } & Total & 2045 (7I.2\%) & $282(32.7 \%)$ & $6.46 \mathrm{E}-88$ \\
\hline & Mild ( $>0$ to $<3$ points) & 795 (27.7\%) & $132(15.3 \%)$ & I.78E-3। \\
\hline & Moderate ( $\geq 3$ to $<7$ points) & 919 (32\%) & $128(14.8 \%)$ & $3.22 \mathrm{E}-19$ \\
\hline & Severe or very severe ( $\geq 7$ to 10 points) & $331(11.5 \%)$ & $22(2.5 \%)$ & $4.22 \mathrm{E}-21$ \\
\hline \multirow[t]{2}{*}{ Gender } & Male & 907 (69.4\%) & $161(30.4 \%)$ & 2.16E-48 \\
\hline & Female & II 38 (72.7\%) & $121(36.2 \%)$ & $4.08 \mathrm{E}-33$ \\
\hline \multirow[t]{6}{*}{ Age } & Mean & $39.41 \pm 14.43$ & $43.73 \pm 14.89$ & $2.42 \mathrm{E}-06$ \\
\hline & $18-29$ years & $631(69.90 \%)$ & $60(35.9 \%)$ & $1.25 \mathrm{E}-13$ \\
\hline & $30-39$ years & $463(70.60 \%)$ & $58(32.4 \%)$ & $5.12 \mathrm{E}-17$ \\
\hline & $40-49$ years & $453(77.00 \%)$ & $64(34 \%)$ & I.69E-23 \\
\hline & $50-59$ years & $263(69.60 \%)$ & $47(31.5 \%)$ & $3.4 \mathrm{E}-12$ \\
\hline & $>60$ years & 235 (67.4\%) & $53(29.4 \%)$ & $1.21 \mathrm{E}-13$ \\
\hline \multirow[t]{6}{*}{ Phototype } & Phototype I & $26 \mid$ (73.9\%) & $26(26 \%)$ & $6.99 \mathrm{E}-15$ \\
\hline & Phototype II & 578 (73.5\%) & 73 (33.2\%) & $2.26 \mathrm{E}-24$ \\
\hline & Phototype III & 733 (70.4\%) & 119 (35.6\%) & $6.42 \mathrm{E}-26$ \\
\hline & Phototype IV & 302 (67.4\%) & $5 \mathrm{I}(34.2 \%)$ & $1.39 \mathrm{E}-09$ \\
\hline & Phototype V & 71 (64.5\%) & $6(20 \%)$ & 0.00229 \\
\hline & Phototype VI & 100 (75.2\%) & 7 (23.3\%) & 3. I2E-05 \\
\hline
\end{tabular}

versus 59\%, p: 0.0005). However, the prevalence of SD was not significantly different in people suffering from pain and in those with intermediate sensations $(72.3 \%$ versus 59\%, p: 0.18).

The severity of SD in case of subjective symptoms was significantly higher than the severity of SD in the absence of symptoms $(4.15 \pm 2.51$ vs $3.56+/ 2.35$, p: 0.03$)$. The intensity of SD was higher in people suffering from pain compared to those suffering from pruritus $(4.85 \pm 2.55$ vs $4.14 \pm 2.51$, p: 0.003). There was no difference in the intensity of SD between patients suffering from pruritus and those suffering from intermediate sensations according to the Visual Analogue Scale $(4.14 \pm 2.51$ vs $3.72 \pm 2.42$, p: 0.07).

VAS sleep disturbance scores were strongly associated with increased pruritus severity ratings ( $\mathrm{r}: 0.25$, p: 6.02 E-27) and pain (r: 0.25, p: 7.93E-21) (Figures 2 and 3 ).

\section{Discussion}

The data from this international, anonymized internet questionnaire conducted with almost 2871 participants provided information aimed at assessing sleep disturbance in patients with cutaneous disorders.
Our study shows that SD is a common problem for patients who have $\mathrm{CD}$, with a high frequency of $\mathrm{SD}$ (71.2\% versus $32.7 \%$ in the control population). In our study, the prevalence of SD in the control population was consistent with that reported in the general population by Soldatos et al, $^{32}$ who established an SD prevalence of $31.6 \%$ in a study carried out on 35,327 subjects from 10 countries. The severity of SD assessed with the Sleep Disturbance Visual Analogue Scale (SD-VAS) was significantly greater in patients with CD $(4.13418 \pm 2.51$ versus $3.54 \pm 2.32$ in control individuals, p: 0.0019). Our study does not report a higher prevalence in women at all ages, as it has been frequently reported. ${ }^{1,3}$ However, we highlighted a higher prevalence of SD after 40 years in females than in males $(47,2 \%$ versus $35.7 \%$ ). The increase in the prevalence of SD in females over the age of 40 can be explained by menopause and the per year increasing prevalence of multimorbidities and psychosocial factors affecting sleep. ${ }^{33}$

The pathogenesis of sleep disorders during CD is multifactorial and can be explained by the direct effects of inflammation, affective disorders ${ }^{34}$ and comorbid psychological conditions ${ }^{35}$ frequently found in patients suffering from CD. ${ }^{36}$ Skin plays an important role in proper sleep activity, including deficits in thermoregulatory 
Table 4 Sleep Disturbance Visual Analogue Scale (SD-VAS) of Patients with Sleep Disturbance

\begin{tabular}{|c|c|c|c|c|c|c|}
\hline & & $\begin{array}{l}\text { SD } \\
\mathbf{N} \\
\text { (\%) }\end{array}$ & $\begin{array}{l}\text { SD VAS } \\
\text { Scores } \\
\text { Mean, Standard } \\
\text { Deviation (SD) }\end{array}$ & $\begin{array}{l}\text { SD VAS } \\
\text { Mild } \\
\text { ( }>0 \text { to }<3 \\
\text { Points) }\end{array}$ & $\begin{array}{l}\text { SD VAS } \\
\text { Moderate } \\
\text { ( } \geq 3 \text { to }<7 \\
\text { Points) }\end{array}$ & $\begin{array}{l}\text { SD VAS } \\
\text { Severe or Very } \\
\text { Severe } \\
\text { ( } \geq 7 \text { to } 10 \\
\text { Points) }\end{array}$ \\
\hline $\begin{array}{l}\text { Cutaneous } \\
\text { disorders }\end{array}$ & Total $n=287 \mid$ & 2045 (7I.2) & $4.13 \pm 2.51$ & 795 (38.9\%) & 919 (44.9\%) & 331 (16.9\%) \\
\hline Control & Total $n=863$ & $282(32.7)$ & $3.54 \pm 2.32$ & I 32 (46.8\% & $128(45.4 \%)$ & $22(7.8 \%)$ \\
\hline $\begin{array}{l}\text { Category of } \\
\text { patients }\end{array}$ & $\begin{array}{l}\text { Symptomatic } n=2689 \\
\text { Pruritis } n=2325 \\
\text { Painn }=159 \\
\text { Intermediate sensations } \\
\mathrm{n}=205 \\
\text { Asymptomatic } \mathrm{n}=182\end{array}$ & $\begin{array}{l}1964(73) \\
1728(74.3) \\
115(72.3) \\
121(59) \\
81(44.5)\end{array}$ & $\begin{array}{l}4.15 \pm 2.51 \\
4.14 \pm 2.51 \\
4.85 \pm 2.55 \\
3.72 \pm 2.42 \\
3.56+/ 2.35\end{array}$ & $\begin{array}{l}756(38.5 \%) \\
676(39.1 \%) \\
27(23.5 \%) \\
53(43.8 \%) \\
39(48.1 \%)\end{array}$ & $\begin{array}{l}884(45 \%) \\
769(44.5 \%) \\
62(53.9 \%) \\
53(43.8 \%) \\
35(43.2 \%)\end{array}$ & $\begin{array}{l}324(16.5 \%) \\
283(16.4 \%) \\
26(22.6 \%) \\
15(12.4 \%) \\
7(8.6 \%)\end{array}$ \\
\hline $\begin{array}{l}\text { Type of Skin } \\
\text { Disorders }\end{array}$ & $\begin{array}{l}\text { Acnen }=1044 \\
\text { Psoriasis } n=163 \\
\text { Atopic dermatitis } n=254 \\
\text { Contact dermatitis } n=147 \\
\text { Rosacea } n=201 \\
\text { Vitiligo } n=50 \\
\text { Seborrheic dermatitis } n=195 \\
\text { Scalp disorders } n=216 \\
\text { Photodermatosis } n=422 \\
\text { Others skin disorders } \\
n=179\end{array}$ & $\begin{array}{l}715(68.5) \\
114(69.9) \\
183(72) \\
116(78.9) \\
139(69.2) \\
41(82.0) \\
139(71.3) \\
168(77.8) \\
319(75.6) \\
111(62.0)\end{array}$ & $\begin{array}{l}4.02 \pm 2.51 \\
3.92 \pm 2.40 \\
4.01 \pm 2.49 \\
3.90 \pm 2.33 \\
4.20+/ 2.53 \\
4.59 \pm 2.86 \\
4.05 \pm 2.47 \\
3.97 \pm 2.48 \\
4.70 \pm 2.55 \\
3.93 \pm 2.44\end{array}$ & $\begin{array}{l}282(39.4 \%) \\
50(43.9 \%) \\
77(42.1 \%) \\
47(40.5 \%) \\
55(39.6 \%) \\
15(36.6 \%) \\
54(38.8 \%) \\
70(41.7 \%) \\
97(30.4 \%) \\
48(43.2 \%)\end{array}$ & $\begin{array}{l}323(45.2 \%) \\
50(43.9 \%) \\
8 I(44.3 \%) \\
56(48.3 \%) \\
6 I(43.9 \%) \\
16(39.0 \%) \\
6 I(43.9 \%) \\
76(45.2 \%) \\
15 I(47.3 \%) \\
44(39.6 \%)\end{array}$ & $\begin{array}{l}110(15.4 \%) \\
14(12.3 \%) \\
25(13.7 \%) \\
13(11.2 \%) \\
23(16.5 \%) \\
10(24.4 \%) \\
24(17.3 \%) \\
22(13.1 \%) \\
71(22.3 \%) \\
19(17.1 \%)\end{array}$ \\
\hline Gender & $\begin{array}{l}\text { Male } n=1306 \\
\text { Female } n=1565\end{array}$ & $\begin{array}{l}907(69.4) \\
1138(72.7)\end{array}$ & $\begin{array}{l}3.84 \pm 2.41 \\
4.36 \pm 2.56\end{array}$ & $\begin{array}{l}393(43.3 \%) \\
402(35.3 \%)\end{array}$ & $\begin{array}{l}401(44.2 \%) \\
518(45.5 \%)\end{array}$ & $\begin{array}{l}113(12.5 \%) \\
218(19.2 \%)\end{array}$ \\
\hline Age & $\begin{array}{l}18-29 \text { years } n=903 \\
30-39 \text { years } n=656 \\
40-49 \text { years } n=588 \\
50-59 \text { years } n=37 \\
>60 \text { years } \\
n=346\end{array}$ & $\begin{array}{l}631 \\
463(69.9) \\
453(77.0) \\
263(69.6) \\
235(67.9)\end{array}$ & $\begin{array}{l}3.98 \pm 2.33 \\
3.98 \pm 2.40 \\
4.17 \pm 2.58 \\
4.49 \pm 2.81 \\
4.35 \pm 2.62\end{array}$ & $\begin{array}{l}236(37.4 \%) \\
184(39.7 \%) \\
188(41.5 \%) \\
99(37.6 \%) \\
88(37.4 \%)\end{array}$ & $\begin{array}{l}313(49.6 \%) \\
222(47.9 \%) \\
180(39.7 \%) \\
104(39.5 \%) \\
100(42.6 \%)\end{array}$ & $\begin{array}{l}82(13.0 \%) \\
57(12.3 \%) \\
85(18.8 \%) \\
60(22.8 \%) \\
47(20.0 \%)\end{array}$ \\
\hline
\end{tabular}

mechanisms, body temperature and sleep onset. ${ }^{35,37,38} \mathrm{SD}$, especially with regard to chronicity, can complicate the course of $\mathrm{CD}$ or contribute to the aggravation of dermatological symptoms. ${ }^{4,11,18,24}$

Stress is a well-known factor that can trigger or enhance $\mathrm{CD}$ such as psoriasis, and that can cause a majoration of pruritus, pain or skin inflammation. It can as well have a negative influence on sleep quality, and cause SD. In their review, Chen et $\mathrm{al}^{39}$ highlight a very likely "brainskin connection", that involves many stress mediators and effector cells, such as central and skin peripheral hypothalamic-pituitary-adrenal axis, sympathetic-adrenal medullary axis, substance $\mathrm{P}$ and neurotrophins.
Indeed, just like the brain has the ability to secrete neromediators in response to stress, there also is a skin peripheral stress response system, which involves cutaneous effector cells (like mast cells or dermal fibroblasts) that have the ability to secrete stress neuromediators.

We found a high prevalence of SD in CD patients without subjective skin symptoms (such as pruritus, pain and intermediate sensations), which suggests that these symptoms are aggravating factors but are unlikely the only reason for SD in patients with $\mathrm{CD}$. Pruritus severity was found to be the primary predictor of sleep quality, and pain severity was the second strongest predictor of sleep interference. Our study presents evidence that pain and 


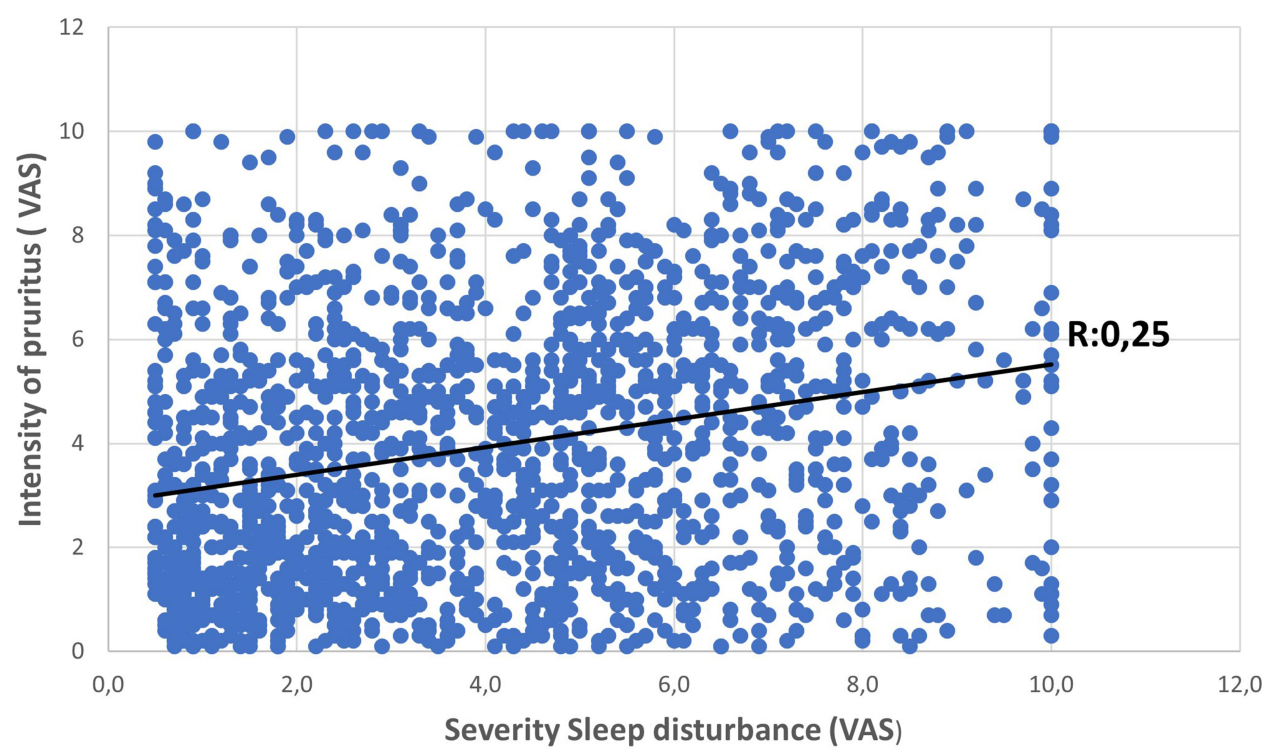

Figure $\mathbf{2}$ Correlation of the intensity of pruritus and the degree of severity disturbance.

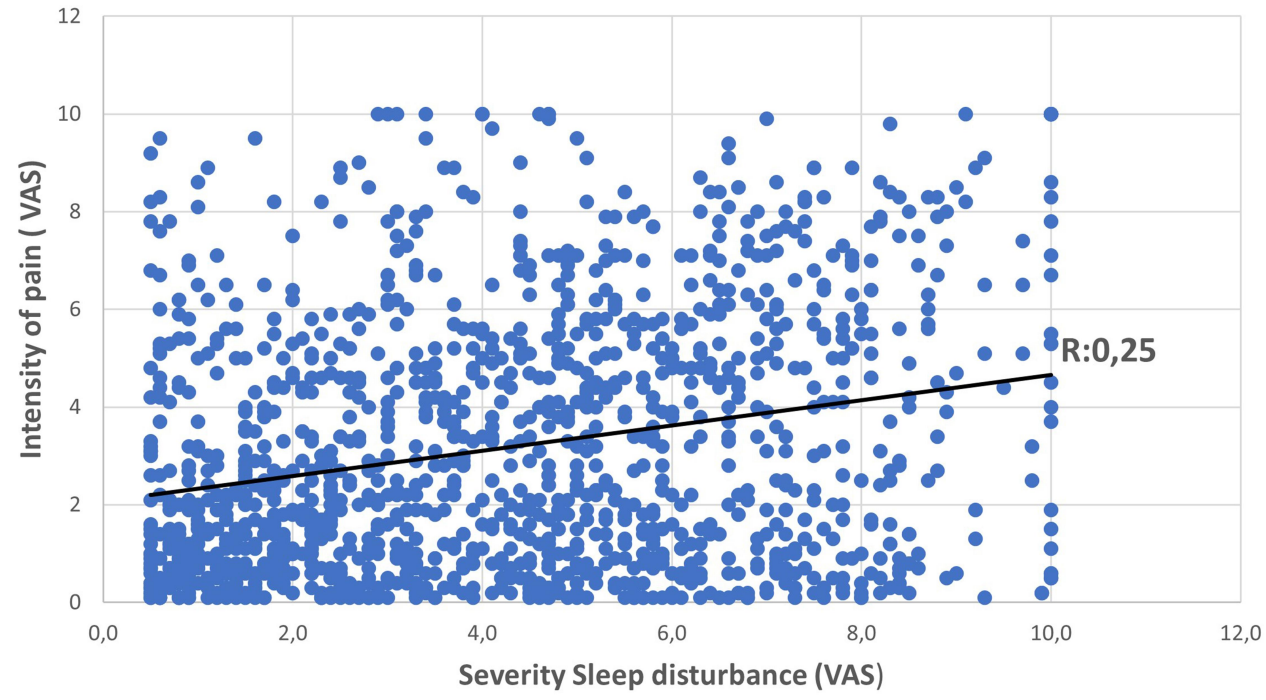

Figure 3 Correlation of the intensity of pain and the degree of sleep disturbance.

pruritus severity correlate negatively with sleep quality. Pain and pruritus both have an antagonistic relationship and share many similarities, including central sensitization processes and a neuropathic component. ${ }^{40-42}$ Pruritus and pain can significantly impair the quality of life and sleep of patients. ${ }^{11,28}$ In our study, we found that intermediate sensations also contributed to sleep disruption in patients with skin conditions. Patients who suffer from such sensations struggle to find the appropriate word for the description, which explains the difficulties in the individualization of these symptoms. Apart from the dermatological symptoms, other factors are likely to play an important role in the onset of $\mathrm{SD}$, such as skin inflammation, as suggested by a recent study which established that patients with inflammatory skin disorders report significantly more fatigue and have higher odds of insomnia compared to patients with noninflammatory skin cancers. ${ }^{11}$

Pathogenesis of SD during chronic inflammation in the course of CD is linked to the activation of microglial cells and astrocytes in brain regions involved in sleep and circadian regulation. ${ }^{11,43,44}$ Interleukin- $1 \beta$ and tumor necrosis factor (TNF) are characterized by their actions 
of sleep regulation ${ }^{45}$ and can lead to symptoms associated with sleep loss, such as sleepiness, fatigue, and poor cognition. ${ }^{46}$ Sleep disturbance itself can have many negative consequences on $\mathrm{CD}$, badly impacting the integrity and composition of the skin. ${ }^{47}$ Alterations in skin barrier function may enhance itch by facilitating the entry of pruritogens. ${ }^{48}$ Acute sleep deprivation has been shown to intensify inflammation of psoriasis in animal studies. ${ }^{49}$ Furthermore, in the event of dysbiosis which is a dysregulation of the skin microbiota (including bacteria, fungi and viruses) associated with $\mathrm{CD}$, pathogens release proteases, which may disrupt the epidermal barrier. Deltatoxin causes mast cell degranulation, which prompt inflammation and itching. 50

Sleep disturbance has deleterious effects on health, including significant quality-of-life impairments, impacts on work and school productivity, driving or transportation accidents due to daytime somnolence, irritability, and poor concentration. SD can contribute to changes in eating habits, with an increased risk of medical comorbidities (obesity, diabetes, hypertension, metabolic syndrome, and cardiovascular disease) and depression. ${ }^{51-57}$

\section{Limitations}

Our study has several limitations. Our sample is a representative group of subjects who consented to take the time to participate in the survey and may be more involved concerning their disease.

Second, it would have been helpful to use a validated instrument to evaluate sleep or an objective measurement of sleep quality (ie, polysomnography and actigraphy). Third, the questionnaire did not detail the existence of associated comorbidities, particularly psychological symptoms, such as anxiety or depression, which can also influence sleep.

\section{Conclusion}

Despite these limitations and the potential bias due to the internet study design, our results confirm, for the first time and on a large international level, the influence of subjective skin symptoms on sleep quality in patients with CD. We reported that $\mathrm{CD}$ without such symptoms can also have a negative influence on sleep quality and that skin unpleasant sensations aggravate SD. Further immunologic or neurologic clinical studies will be necessary to better understand the source of sleep abnormalities in patients with CD and to deepen our knowledge of the roles of the immune system, circadian rhythm, microbiota and environmental factors. Dermatologists need to incorporate the possible presence of an undiagnosed sleep disorder into their assessment of disease. It is important that dermatologists ask general questions about pruritus, pain, intermediate sensations, and sleep with patients during routine evaluations of cutaneous disorder. Kaaz et $\mathrm{al}^{38}$ proposed reliable guidelines concerning the evaluation and management of sleep disorders in chronic dermatological patients.

\section{Funding}

This work was supported by La Roche-Posay Dermatological Laboratories, France.

\section{Disclosure}

Bruno Halioua is a private dermatologist. V. Delvigne and S. Seité are employees of La Roche-Posay, France. Sophie Seite reports personal fees from La Roche-Posay, during the conduct of the study and outside the submitted work. Clara Chelli reports grants from Sanofi, outside the submitted work. The authors report no other potential conflicts of interest for this work.

\section{References}

1. Aminoff MJ, Boller F, Swaab DF. We spend about one-third of our life either sleeping or attempting to do so. Handb Clin Neurol. 2011;98:vii.

2. Katz DA, McHorney CA. Clinical correlates of insomnia in patients with chronic illness. Arch Intern Med. 1998;158(10):1099-1107. doi:10.1001/archinte.158.10.1099

3. Kyle SD, Morgan K, Espie CA. Insomnia and health-related quality of life. Sleep Med Rev. 2010;14(1):69-82. doi:10.1016/j. smrv.2009.07.004

4. Thorburn PT, Riha RL. Skin disorders and sleep in adults: where is the evidence? Sleep Med Rev. 2010;14(6):351-358. doi:10.1016/j. smrv.2009.12.001

5. Gowda S, Goldblum OM, McCall WV, Feldman SR. Factors affecting sleep quality in patients with psoriasis. $J$ Am Acad Dermatol. 2010;63(1):114-123. doi:10.1016/j.jaad.2009.07.003

6. Magin P. Psoriasis and sleep: unravelling the relationship. $\mathrm{Br}$ J Dermatol. 2019;180(6):1289-1290. doi:10.1111/bjd.17875

7. Saçmacı H, Gürel G. Sleep disorders in patients with psoriasis: a cross-sectional study using non-polysomnographical methods. Sleep Breath. 2019;23(3):893-898. doi:10.1007/s11325-019-01820-8

8. Krajewska-Włodarczyk M, Owczarczyk-Saczonek A, Placek W. Sleep disorders in patients with psoriatic arthritis and psoriasis. Reumatologia. 2018;56(5):301-306. doi:10.5114/reum.2018.79501

9. Yu SH, Attarian H, Zee P, Silverberg JI. Burden of sleep and fatigue in US adults with atopic dermatitis. Dermatitis. 2016;27(2):50-58. doi:10.1097/DER.0000000000000161

10. Yano C, Saeki H, Ishiji T, et al. Impact of disease severity on sleep quality in Japanese patients with atopic dermatitis. J Dermatol Sci. 2013;72(2):195-197. doi:10.1016/j.jdermsci.2013.06.010

11. Mostaghimi L, Hetzel S. Insomnia and other sleep complaints in inflammatory versus noninflammatory skin disorders: an observational case-control study. Int J Dermatol. 2019;58(8):976-981. doi:10.1111/ijd.14488 
12. Vachiramon V, Onprasert W, Harnchoowong S, Chanprapaph K Prevalence and clinical characteristics of itch in vitiligo and its clinical significance. Biomed Res Int. 2017;2017:5617838. doi: $10.1155 / 2017 / 5617838$

13. Seo HM, Kim TL, Kim JS. The risk of alopecia areata and other related autoimmune diseases in patients with sleep disorders: a Korean population-based retrospective cohort study. Sleep. 2018;41:9. doi:10.1093/sleep/zsy111

14. Misery L, Wolkenstein P, Amici JM, et al. Consequences of acne on stress, fatigue, sleep disorders and sexual activity: a population-based study. Acta Derm Venereol. 2015;95(4):485-488. doi:10.2340/ 00015555-1998

15. Maurer M, Ortonne JP, Zuberbier T. Chronic urticaria: an internet survey of health behaviours, symptom patterns and treatment needs in European adult patients. $\mathrm{Br} J$ Dermatol. 2009;160(3):633-641. doi:10.1111/j.1365-2133.2008.08920.x

16. Latif O. Impact of severity of CSU on sleep, anxiety and depressive symptoms in adults. Eur Acad Res. 2017;5:1145-1157.

17. Konda D, Chandrashekar L, Rajappa M, Kattimani S, Thappa DM, Ananthanarayanan PH. Serotonin and interleukin-6: association with pruritus severity, sleep quality and depression severity in Prurigo Nodularis. Asian $J$ Psychiatr. 2015;17:24-28. doi:10.1016/j. ajp.2015.07.010

18. Kaaz K, Szepietowski JC, Matusiak Ł. Influence of itch and pain on sleep quality in patients with hidradenitis suppurativa. Acta Derm Venereol. 2018;98(8):757-761. doi:10.2340/00015555-2967

19. Adamo D, Ruoppo E, Leuci S, Aria M, Amato M, Mignogna MD. Sleep disturbances, anxiety and depression in patients with oral lichen planus: a case-control study. J Eur Acad Dermatol Venereol. 2015;29(2):291-297. doi:10.1111/jdv.12525

20. Jeon C, Yan D, Nakamura M, et al. Frequency and management of sleep disturbance in adults with atopic dermatitis: a systematic review. Dermatol Ther (Heidelb). 2017;7(3):349364. doi:10.1007/ s13555-017-0192-3

21. Kong TS, Han TY, Lee JH, Son SJ. Correlation between severity of atopic dermatitis and sleep quality in children and adults. Ann Dermatol. 2016;28(3):321-326. doi:10.5021/ad.2016.28.3.321

22. Gupta MA, Simpson FC, Gupta AK. Psoriasis and sleep disorders: a systematic review. Sleep Med Rev. 2016;29:63-75. doi:10.1016/j. smrv.2015.09.003

23. Jensen P, Zachariae C, Skov L, Zachariae R. Sleep disturbance in psoriasis: a case-controlled study. $\mathrm{Br} J$ Dermatol. 2018;179 (6):1376-1384. doi:10.1111/bjd.16702

24. Kaaz K, Szepietowski JC, Matusiak Ł. Influence of itch and pain on sleep quality in atopic dermatitis and psoriasis. Acta Derm Venereol. 2019;99(2):175-180. doi:10.2340/00015555-3065

25. Pärna E, Aluoja A, Kingo K. Quality of life and emotional state in chronic skin disease. Acta Derm Venereol. 2015;95(3):312-316. doi:10.2340/00015555-1920

26. Gezer O, Batmaz İ, Sariyildiz MA, et al. Sleep quality in patients with psoriatic arthritis. Int J Rheum Dis. 2017;20(9):1212-1218. doi:10.1111/1756-185X.12505

27. O’Neill JL, Chan YH, Rapp SR, Yosipovitch G. Differences in itch characteristics between psoriasis and atopic dermatitis patients: results of a web-based questionnaire. Acta Derm Venereol. 2011;91 (5):537-540. doi:10.2340/00015555-1126

28. Yosipovitch G, Goon A, Wee J, Chan YH, Goh CL. The prevalence and clinical characteristics of pruritus among patients with extensive psoriasis. Br J Dermatol. 2000;143(5):969-973. doi:10.1046/j.13652133.2000.03829.x

29. Ljosaa TM, Rustoen T, Mörk C, et al. Skin pain and discomfort in psoriasis: an exploratory study of symptom prevalence and characteristics. Acta Derm Venereol. 2010;90(1):39-45. doi:10.2340/00015555-0764
30. Misery L. Le prurit: des avancées physiopathologiques considérables [Pruritus: considerable progress in pathophysiology]. Med Sci (Paris). 2014;30(12):1123-1128. doi:10.1051/medsci/20143012015

31. Parrott AC, Hindmarch I. Factor analysis of a sleep evaluation questionnaire. Psychol Med. 1978;8(2):325-329. doi:10.1017/ S0033291700014379

32. Soldatos CR, Allaert FA, Ohta T, Dikeos DG. How do individuals sleep around the world? Results from a single-day survey in ten countries. Sleep Med. 2005;6(1):5-13. doi:10.1016/j. sleep.2004.10.006

33. Miner B, Kryger MH. Sleep in the aging population. Sleep Med Clin. 2017;12(1):31-38. doi:10.1016/j.jsmc.2016.10.008

34. Dalgard FJ, Gieler U, Tomas-Aragones L, et al. The psychological burden of skin diseases: a cross-sectional multicenter study among dermatological out-patients in 13 European countries. J Invest Dermatol. 2015;135(4):984-991. doi:10.1038/jid.2014.530

35. Gupta MA, Gupta AK. Psychiatric and psychological co-morbidity in patients with dermatologic disorders: epidemiology and management. Am J Clin Dermatol. 2003;4(12):833-842. doi:10.2165/00128071200304120-00003

36. Singareddy R, Moin A, Spurlock L, Merritt-Davis O, Uhde TW. Skin picking and sleep disturbances: relationship to anxiety and need for research. Depress Anxiety. 2003;18(4):228-232. doi:10.1002/ da. 10153

37. Liao KM, Ho CH, Lee HF, Yu CH, Wang JJ, Liang FW. Risk factors of chronic urticaria among nurses with insomnia: a nationwide population-based study. Medicine (Baltimore). 2019;98(49):e18059. doi:10.1097/MD.0000000000018059

38. Kaaz K, Szepietowski JC, Matusiak Ł. Sleep quality among adult patients with chronic dermatoses. Postepy Dermatol Alergol. 2019;36 (6):659-666. doi:10.5114/ada.2019.84007

39. Chen Y, Lyga J. Brain-skin connection: stress, inflammation and skin aging. Inflamm Allergy Drug Targets. 2014;13(3):177-190. doi:10.2174/1871528113666140522104422

40. Anzelc M, Burkhart CG. Pain and Pruritus: a study of their similarities and differences. Int $J$ Dermatol. 2020;59(2):159-164. doi:10.1111/ijd.14678

41. Ständer S, Schmelz M. Chronic itch and pain-similarities and differences. Eur J Pain. 2006;10(5):473-478. doi:10.1016/j. ejpain.2006.03.005

42. Liu T, Ji RR. New insights into the mechanisms of itch: are pain and itch controlled by distinct mechanisms? Pflugers Arch. 2013;465 (12):1671-1685. doi:10.1007/s00424-013-1284-2

43. Morris G, Stubbs B, Köhler CA, et al. The putative role of oxidative stress and inflammation in the pathophysiology of sleep dysfunction across neuropsychiatric disorders: focus on chronic fatigue syndrome, bipolar disorder and multiple sclerosis. Sleep Med Rev. 2018;41:255-265. doi:10.1016/j.smrv.2018.03.007

44. Krueger JM, Rector DM, Churchill L. Sleep and cytokines. Sleep Med Clin. 2007;2(2):161-169. doi:10.1016/j.jsmc.2007.03.003

45. Gupta MA, Gupta AK. Sleep-wake disorders and dermatology. Clin Dermatol. 2013;31(1):118-126. doi:10.1016/j. clindermatol.2011.11.016

46. Jewett KA, Krueger JM. Humoral sleep regulation; interleukin-1 and tumor necrosis factor. Vitam Horm. 2012;89:241-257.

47. Kahan V, Andersen ML, Tomimori J, Tufik S. Can poor sleep affect skin integrity? Med Hypotheses. 2010;75(6):535-537. doi:10.1016/j. mehy.2010.07.018

48. Lavery MJ, Stull C, Kinney MO, Yosipovitch G. Nocturnal Pruritus: the battle for a peaceful night's sleep. Int J Mol Sci. 2016;17(3):425. doi:10.3390/ijms 17030425

49. Hirotsu C, Rydlewski M, Araújo MS, Tufik S, Andersen ML. Sleep loss and cytokines levels in an experimental model of psoriasis. PLoS One. 2012;7(11):e51183. doi:10.1371/journal.pone.0051183 
50. Kim HS, Yosipovitch G. The skin microbiota and itch: is there a link? J Clin Med. 2020;9(4):1190. doi:10.3390/jcm9041190

51. Thomas SJ, Calhoun D. Sleep, insomnia, and hypertension: current findings and future directions. $J$ Am Soc Hypertens. 2017;11 (2):122-129. doi:10.1016/j.jash.2016.11.008

52. Chiu HY, Hsieh CF, Chiang YT, et al. Concomitant sleep disorders significantly increase the risk of cardiovascular disease in patients with psoriasis. PLoS One. 2016;11(1):e0146462. doi:10.1371/journal. pone. 0146462

53. Van Cauter E, Spiegel K, Tasali E, Leproult R. Metabolic consequences of sleep and sleep loss. Sleep Med. 2008;9 Suppl 1:S23-8. doi:10.1016/S1389-9457(08)70013-3

54. van Leeuwen WM, Lehto M, Karisola $P$, et al. Sleep restriction increases the risk of developing cardiovascular diseases by augmenting proinflammatory responses through IL-17 and CRP. PLoS One. 2009;4(2):e4589. doi:10.1371/journal.pone.0004589
55. Daley M, Morin CM, LeBlanc M, Grégoire JP, Savard J, Baillargeon L. Insomnia and its relationship to health-care utilization, work absenteeism, productivity and accidents. Sleep Med. 2009;10 (4):427-438. doi:10.1016/j.sleep.2008.04.005

56. Spiegel K, Leproult R, Van Cauter E. Impact of sleep debt on metabolic and endocrine function. Lancet. 1999;354 (9188):1435-1439. doi:10.1016/S0140-6736(99)01376-8

57. Knutson KL, Van Cauter E. Associations between sleep loss and increased risk of obesity and diabetes. Ann N Y Acad Sci. 2008;1129:287-304. doi:10.1196/annals.1417.033

\section{Publish your work in this journal}

Clinical, Cosmetic and Investigational Dermatology is an international, peer-reviewed, open access, online journal that focuses on the latest clinical and experimental research in all aspects of skin disease and cosmetic interventions. This journal is indexed on CAS.
The manuscript management system is completely online and includes a very quick and fair peer-review system, which is all easy to use. Visit http://www.dovepress.com/testimonials.php to read real quotes from published authors. 